\title{
DIÁLOGO DE MULHERES DE FRONTEIRA NO CONTEXTO DA UNIVERSIDADE POPULAR DOS MOVIMENTOS SOCIAIS: NOVAS METODOLOGIAS E AGENDAS
}

\author{
Vanessa Marx ${ }^{1}$ \\ Lilian Celiberti ${ }^{2}$
}

\section{Globalização contra-hegemônica e a perspectiva decolonial de América Latina ${ }^{3}$}

O contexto mundial vem sendo marcado pelo fenômeno da globalização. Este fenômeno influencia cada vez mais a dinâmica de trabalho e agenda dos movimentos sociais. Os movimentos sociais atuam nas localidades, lugar onde expressam desejos, conflitos e disputam com outros atores, entre eles o Estado, por espaços no processo de formulação e implementação de políticas públicas.

Apesar do território ser o lugar onde exercem sua ação política e suas lutas, a globalização veio internacionalizar as agendas dos movimentos sociais. O impacto que a globalização trouxe poderia ser traduzido em mudanças na vida das pessoas, na forma de se relacionar, na política e nas instituições. As relações dos diversos atores que atuam no cenário global se estabelecem cada vez mais por meios virtuais e conectados em redes produzindo "ação à distância" (Held, 1997: 42).

O capital e o trabalho circulam sem barreiras entre as regiões e os países gerando desigualdade, isso se deve ao crescimento do setor privado e das relações transnacionais, que geraram flexibilidade e instabilidade nas relações laborais. Esta dinâmica é percebida com maior clareza nas zonas de fronteira. Esta globalização vem se traduzindo em um desenvolvimento geográfico desigual (Harvey, 2006).

No cenário globalizado aparecem novos atores, que podem ter um papel importante na arena internacional, entre eles os movimentos sociais. Esta redistribuição de poder nos situa no âmbito político-institucional, que junto com a influência da política econômica dos países desenvolvidos e do mercado financeiro internacional nos

\footnotetext{
${ }^{1}$ Universidade Federal do Rio Grande do Sul, Brasil.

${ }^{2}$ Cotidiano Mujer, Uruguai; Articulação Feminista Marcosur.

${ }^{3}$ As autoras agradecem às setenta mulheres que participaram da oficina mulheres em diálogo de fronteira e as instituições descritas no texto que apoiaram esta iniciativa.
} 
ajuda a entender o que significa a globalização neoliberal e o surgimento do Fórum Social Mundial (FSM) ${ }^{4}$.

O neoliberalismo surgiu como resposta ao Estado intervencionista e de bemestar na América do Norte e Europa. Buscava estabelecer outro tipo de capitalismo, sem regras. A partir desta base, foram implementadas políticas de altas taxas de juros, via livre para os fluxos financeiros, redução dos impostos para os sujeitos com salários mais altos; gerando altas taxas de desemprego, um amplo programa de privatizações e o desmantelamento de alguns sindicatos.

Com este processo coloca-se em evidência o conceito de globalização hegemônica. Este tipo de globalização poderia ser entendida como a globalização neoliberal exercida de forma hegemônica sob as regras dos Estados Unidos.

Como contraponto à globalização hegemônica, surge outro conceito, o da globalização contra-hegemônica. A partir do Fórum Social Mundial foi construída gradualmente uma globalização alternativa à globalização neoliberal, uma globalização contra-hegemônica, desde os movimentos sociais. Esta globalização está intrinsecamente relacionada à idéia de utopia como nos expõe Sousa Santos (2002: 57):

\begin{abstract}
Globalização contra-hegemônica seria a articulação transnacional dos movimentos, associações e organizações que defendem os interesses e grupos subalternos ou marginalizados pelo capitalismo global. A globalização contra-hegemônica é fundamental para organizar e disseminar estratégias, políticas eficazes, criar alternativas ao livre comércio como às iniciativas de comércio justo, e garantir o acesso das ONG's dos países periféricos ao conhecimento teórico e as redes políticas onde emergem as políticas hegemônicas que afetam a estes países.
\end{abstract}

Os impactos negativos da globalização neoliberal e sua repercussão na agenda dos movimentos sociais mostram a multidimensionalidade deste fenômeno histórico nas mais variadas dimensões: econômica, sóciocultural, de informação, tecnológica, institucional e política. Mas a análise da globalização parte de um fenômeno

\footnotetext{
${ }^{4}$ O Fórum Social Mundial (FSM) nasceu em Porto Alegre, no ano de 2001 contrapondo-se ao Fórum Econômico de Davos. O FSM vem sendo organizado pelos movimentos sociais com o lema: "Outro mundo é possível". Estes movimentos questionam a globalização neoliberal e propõem alternativas a este modelo. Reúne ativistas de diversas partes do planeta. Em seu processo de expansão o Fórum Social já foi organizado em outras cidades do mundo, do sul global, como Mumbai (Índia) e Nairóbi (Quênia), por exemplo.
} 
caracterizado como predominantemente econômico e marcado pela aceleração dos fluxos financeiros.

A globalização vem influindo na vida dos seres humanos e na maneira de organizar-se em sociedade. A forma que alguns indivíduos exercem os seus direitos e cumprem suas obrigações pode dar-se de forma isolada, atendendo o seu próprio bemestar, enquanto outros indivíduos atuam e influenciam na sociedade em que vivem, priorizando o coletivo.

No contexto da globalização neoliberal onde a lógica da competitividade é mostrada como um valor, alguns elementos são o resultado das transformações que vem acontecendo em alguns países do globo como: a flexibilização laboral, a diferença salarial entre homens e mulheres, a exclusão social e o aumento da pobreza, a precariedade da educação, e da brecha digital, que tem um impacto social e cultural em uma sociedade complexa e globalizada.

Neste contexto a América Latina, depois da década perdida e das recomendações de países do Norte Global e das agências internacionais, experimentou uma reorientação de seus valores e políticas criando uma nova episteme centrada na perspectiva decolonial para descontruir, desde o sul, conceitos sedimentados a partir do Norte-Global.

Este movimento nos impulsiona a construir diálogos interculturais, como por exemplo entre feministas e não feministas de diferentes movimentos, conectados com um conjunto de organizações e redes de América Latina. Com a possibilidade, neste novo contexto, de reforçar a cooperação sul-sul e as dinâmicas de fronteira, faz-se importante analisar como se situam os atores sociais nesta nova correlação de forças.

Este contexto Latino-Americano se articula com a perspectiva do decolonial, como bem nos expõe Quijano (2002), ao falar sobre a colonialidade do poder, o capitalismo como padrão universal da exploração social, o Estado-Nação como sua variante hegemônica, e o eurocentrismo como forma hegemônica de controle da subjetividade/intersubjetividade e no modo de produzir conhecimento.

Alguns movimentos sociais criam novos paradigmas que atenuam os efeitos perversos do neoliberalismo, através de novas esperanças e alternativas a este modelo.

Poderíamos dizer que com as experiências de radicalização da democracia e de inclusão social os atores sociais buscam-se novas formas de influir na política. A inovação consistiria no aumento da consciência de que é necessário ampliar esfera 
pública política, através da multiplicação de experiências de democracia participativa, da inserção dos atores sociais excluídos e da criação de canais de diálogo entre os saberes populares intrínsecos nas lutas e nas práticas do cotidiano dos movimentos sociais.

Tal ampliação da esfera pública iria além de uma idéia de rede de comunicação de conteúdos, da tomada de posições e opiniões (Habermas, 1997) frente a outros atores, ela poderia constituir um lócus de aprendizado mútuo e de tomada de consciência das necessidades dos movimentos sociais, de como reforçar suas agendas internas e de como exercer influência em temas públicos de caráter interno ou internacional.

Este aprendizado mútuo dos movimentos sociais no plano internacional tem um caráter não só de emancipação social, mas também de uma preocupação pela diversidade cultural e pela radicalização da democracia onde: "Pensar a democracia como ruptura positiva na trajetória de uma sociedade implica em abordar elementos culturais dessa mesma sociedade" (Sousa Santos e Avritzer, 2009: 52).

Partindo dos elementos culturais é que a troca de saberes se faz mais complexa e ao mesmo tempo mais desafiante. A diversidade cultural constitui um elemento central ao trabalhar com movimentos sociais internacionalizados, a diferença aparece como um recurso, como uma riqueza, como elemento essencial para confrontar diferentes visões, perspectivas e significados.

É com este anseio de atuar no contexto global construído pelos movimentos sociais e de colaborar para um maior entendimento das lutas e saberes destes atores é que nasce a Universidade Popular dos Movimentos Sociais (UPMS) idealizada por Boaventura de Sousa Santos e inserida no projeto ALICE da Universidade de Coimbra ${ }^{5}$.

A UPMS nasce em um contexto adverso, o da globalização neoliberal, ela se insere em um movimento dos movimentos, o Fórum Social Mundial, e finalmente ela busca a emancipação dos movimentos sociais através do intercâmbio dos saberes formais e informais intrínsecos a vida dos que militam nestas esferas (Marx, 2012).

\footnotetext{
${ }^{5}$ Projeto Alice http://alice.ces.uc.pt/en/?lang=pt acessado em 03/01/2017.
} 
O objeto de estudo deste trabalho versa sobre o processo da UPMS na construção do diálogo de mulheres de fronteira.

A UPMS tem a intenção de contribuir para que seja alcançada uma justiça social global por meio do trabalho de uma justiça cognitiva global. Ela constitui-se como o espaço para que o conhecimento da globalização alternativa seja tão global quanto ela e que, nesse processo, as ações transformadoras sejam mais esclarecidas e eficazes e os seus protagonistas, mais competentes e reflexivos.

A formação pretendida pela UPMS é de formar ativistas e líderes comunitários dos movimentos sociais e das ONGs, fornecendo-lhes quadros analíticos e teóricos que lhes permitam aprofundar a compreensão e reflexão sobre suas práticas, de seus métodos e de seus objetivos. Por outro lado, formar cientistas sociais/intelectuais/artistas interessados no estudo dos novos processos de transformação social, dando-lhes a possibilidade de um diálogo direto com os seus protagonistas e assim identificar e, na medida do possível, eliminar a discrepância entre os quadros teóricos e analíticos em que foram treinados e as necessidades e aspirações concretas das novas práticas transformadoras. ${ }^{6}$

Estas práticas transformadoras se expressam por meio da ecologia dos saberes que se constitui como uma contra epistemologia, onde se cruzam os saberes formal e popular. Para Sousa Santos (2007: 89)

\begin{abstract}
Num regime de ecologia de saberes, a busca de intersubjetividade é tão importante quanto complexa. Uma vez que diferentes práticas de conhecimento têm lugar em diferentes escalas espaciais e com diferentes durações e ritmos, a intersubjetividade requer a disposição para conhecer e agir em diferentes escalas (interescalaridade) e com diferentes durações (intertemporalidade). Muitas das experiências subalternas de resistência são locais ou foram localizadas e assim tornadas irrelevantes ou inexistentes pelo conhecimento abissal moderno, o único capaz de gerar experiências globais.
\end{abstract}

Neste sentido realização de oficinas da UPMS permite intercambiar experiências, valorizar soluções locais e contribuir para operacionalizar redes transescalares que empoderem os movimentos sociais e ao mesmo tempo crie novas pedagogias e epistemologias a partir do diálogo.

\footnotetext{
${ }^{6}$ Uma cartografia destas experiências e práticas sociais postas em movimento pela UPMS pode ser verificada em: http://www.universidadepopular.org/pages/pt/oficinas.php. Acessado em 28/05/2016.
} 
O fortalecimento dos movimentos sociais vem demandando cada vez mais a apropriação de ferramentas teóricas e metodológicas que contribuam com a qualificação da sua intervenção. A experiência de construção dos movimentos implica também em uma apropriação do conhecimento científico como uma ferramenta em suas lutas. Por outro lado, essa própria luta é em si mesma produtora de novos saberes, que precisam ser sistematizados, integrados e qualificados.

\section{Novas pedagogias e epistemes a partir do diálogo}

Para poder avançar em uma "pedagogia da alteridade", como descreve Arturo Escobar (2003), é necessário ver o outro/outra em sua radical diferença, sem pretensão de assimilação e/ou conquista. $\mathrm{O}$ encontro de experiências políticas e práticas culturais subalternas, é um campo de interação relativamente recente, que pode chegar a criar uma "epistemologia de fronteira" (Mignolo, 2011; Walsh, 2005), cuja originalidade consiste na diversidade e no cruzamento de varias identidades, subjetividades e territórios.

Para desenvolver um pensamento de fronteira é necessario revisar conceitualmente as categorías e os mapas de caminhos com os quais interpretamos os problemas, condição necessária para abrir novas perspectivas críticas. Desde cada práxis política se constroem sentidos de interpelação e disputas, que geram novos intersticios e espessores, por isto a ação dos atores em movimentos produz conhecimentos fronteiriços, que possibilitam articular e traduzir perspectivas emancipatorias.

Assumimos como perspectiva política um feminismo que, "não é movimento que ordena, que centraliza que define modelos a seguir" como expõe Betânia Ávila (2007). Por isto a teoria feminista e particularmente o ativismo feminista está sempre em processo de revisão e ressignificação de conceitos e categorias. Nesta direção a líder afrodescendente Sueli Carneiro fala sobre a necessidade de tornar negro o feminismo e questiona quais seriam os conteúdos que as mulheres negras poderiam aportar na cena política, além do "toque de cor" nas propostas de gênero. (Carneiro, 2002).

Para as feministas afro, e para as indígenas, a disputa, se dá tanto no pensamento teórico feminista, como no campo político. Por isto se abre um debate que surge de outros lugares de enunciação, de outras experiências sociais, de outras dores e marcas. 
Avançar em novas concepções supõe traçar um caminho de rupturas teóricas, descolonizações e questionamentos simultâneos ao etnocentrismo, ao patriarcado e a heteronormatividade. Supõe diálogos e confrontações que abrem espaço aos conflitos, tanto em discursos como em práticas políticas. (Celiberti, 2012).

Como ressaltou Quijano, na América Latina: “a raça se converteu no primeiro critério fundamental para a distribuição da população mundial em lugares e papéis na estrutura de poder da nova sociedade. Em outros termos, no modo básico de classificação social universal da população mundial“" (Quijano, 2000: 246).

Quijano (2000) não desenvolve, por outro lado, a particular articulação entre racismo e sexismo deixando de alguma forma incompleta a desobediência epistêmica de que descreve Mignolo (Mignolo, 2011: 8) e os teóricos da colonialidade do saber-poder. A teoria crítica requer de um enfoque que incorpore o gênero, a raça e a natureza, em seu marco conceitual e político. As contribuições das feministas decoloniais são fundamentais nesta tarefa. Analisar as consequências específicas da racialização patriarcal na vida das mulheres negras e mestiças da América Latina, implica colocar foco nas experiências sociais diferenciadas entre mulheres negras, mestiças e brancas.

As mulheres negras interpelam, questionam, denunciam o feminismo branco por universalizar as experiências e as opressões das mulheres brancas ocidentais, ignorando o outro, as mulheres negras, as mulheres indígenas propondo desta forma a descolonização do pensamento, imaginação simbólica e ação. Invisibilidade, negação e esquecimento das experiências sociais de "sujeitos sem história" foi a operação simbólica da modernidade, nas nações latino-americanas.

Desde o feminismo negro adverte-se que não se trata de renomear, já que a conjunção de gênero-raça interpela em si mesma as categorias tal como foram formuladas. Neste sentido Hazel Carby (2012: 209) descreve que:

La experiencia de las mujeres negras no entra en los parámetros del paralelismo (género-raza). La principal razón para no emplear paralelismos es el hecho de que las mujeres negras están sujetas simultáneamente a las opresiones del patriarcado, la clase y la «raza», lo que hace que su posición y su experiencia no sólo resulten marginales, sino también invisibles. 
Invisibilizar, silenciar, suprimir faz parte da lógica de não existência, e esta adquire matizes próprios segundo cada realidade histórica.

Para transformar as ausências em presenças Boaventura de Sousa Santos (2001) propõe partir da análise das lógicas de não existência que se retroalimentam de tal forma que, terminamos aceitando que existe uma única forma de conhecimento e de saber, um único tempo linear, uma única historia, um único destino onde as diferenças se naturalizam, e as classificações sociais se tornam essenciais a natureza dos seres humanos.

A classificação sexual e racial são manifestações eloquentes desta lógica. A inferioridade "naturalizada" das mulheres, dos/das negros/as e dos indígenas fez parte, não somente das estratégias de dominação centrais nas conquistas e expansões capitalistas, mas tem sido objeto de análise e fundamento de dominação. Os atributos desta dominação se estabeleceram desde o ser mulher, o ser negro ou negra ou o ser indígena como se não fossem relações sociais de dominação as determinantes do sistema hierárquico.

A possibilidade de estabelecer um diálogo horizontal sobre os questionamentos, as críticas, as subjetividades, os sonhos e os desejos e também sobre as perdas e preconceitos que surgem das relações sociais cotidianas e expressam imaginários colonizados poderia ser uma ferramenta para a construção coletiva de novos imaginários.

O diálogo plural é uma ferramenta política e também uma proposta emancipadora em si mesma, já que abre a possibilidade de fazer política feminista a partir da diversidade e com uma pluralidade de olhares. O cenário político da América Latina, e o feminismo de mil rostos diferentes, estabelece diálogos entre imaginários construídos nas lutas e protagonistas de suas histórias, sendo este um campo fértil para a produção epistemológica e política. Encontrar alternativas supõe reconhecer em cada luta sua contribuição crítica, ainda quando perdurem imaginários colonizados a serem desconstituídos.

Boaventura de Sousa Santos expõe que os grupos sociais interessados na emancipação não podem hoje começar a defender a coerência e a eficácia de alternativas emancipatórias sem correr o risco de aprofundar sua incoerência e credibilidade. É necessário percorrer um caminho de debate, de confluência de 
experiências e de reconhecimento das novas formas de sociabilidade, de novas subjetividades emanciapatórias, de novas culturas políticas para poder:

Reinventar un mapa emancipatorio que no se convierta gradualmente en un nuevo mapa regulatorio y reinventar una subjetividad individual y colectiva capaz de usar y querer usar ese mapa, sería el camino para delinear un trayecto progresista a través de una doble transición, epistemológica por un lado y societal por otro. (Sousa Santos, 2001: 330).

Por isto a metodologia da troca de saberes entre o acadêmico e o popular nos instiga a imaginar em uma ecologia de saberes onde intelectuais e ativistas se dispõem a pensar em novos espaços e arenas de diálogo para reformar e fortalecer alianças e interações, como na experiência da Universidade Popular dos Movimentos Sociais que expomos: a continuação em que ativistas e acadêmicos se propuseram a organizar uma oficina específica, desde o sul da América Latina, sobre mulheres de fronteira.

\section{A Universidade Popular dos Movimentos Sociais: mulheres em diálogo de fronteira}

A Universidade Popular dos Movimentos Sociais (UPMS) nasceu no Fórum Social Mundial (FSM) de 2003, ocorrido em Porto Alegre, Rio Grande do Sul, Brasil. A UPMS surge da constatação de que além do FSM deveriam ser criados meios onde os movimentos pudessem intercambiar seus saberes e formar-se de forma coletiva e intercultural, a fim de aumentar o conhecimento.

A UPMS tem a intenção de contribuir para que seja alcançada uma justiça social global por meio do trabalho de uma justiça cognitiva global. O objetivo geral da UPMS é contribuir para que o conhecimento da globalização alternativa seja tão global quanto ela e que, nesse processo, as ações transformadoras sejam mais esclarecidas e eficazes e os seus protagonistas, mais competentes e reflexivos. (Sousa Santos, 2003).

É no marco do processo de enraizamento e expansão da UPMS no mundo que foi organizada a oficina da UPMS: Mulheres em diálogo de fronteira, que aconteceu em Santana do Livramento-Rivera nos dias 7 e 8 de agosto de 2015. 
A organização da oficina foi realizada pela Universidade Federal do Rio Grande do Sul (UFRGS) através de projeto de extensão na Sociologia ${ }^{7}$ com participação da Geografia, pelo coletivo feminista Cotidiano Mujer e o Instituto Nacional de las Mujeres (Inmujeres) do Ministerio de Desarrollo Social (MIDES) de Uruguai, com o apoio da Coordenadoria da Mulher da Prefeitura de Santana do Livramento-Brasil, ONU Mulheres, CIRE e o Centro Universitário de Rivera (CUR) da Universidad de La República.

Participaram deste primeiro encontro de mulheres de fronteira mais de 70 mulheres das localidades fronteiriças uruguaias: Rio Branco, Aceguá, Rivera, Artigas, Chuí, Rocha, Bella Unión, Balneario Lagua Merín, Melo e localidades fronteiriças brasileiras Jaguarão, Santana do Livramento, Bagé e Quaraí.

O objetivo deste encontro foi estabelecer um diálogo sobre os temas de fronteira que envolviam as mulheres, centrando-se principalmente em questões relacionadas com as autonomias: do corpo, econômica e política e territorial onde foram debatidas questões como o trabalho, a segurança social, os direitos laborais das mulheres, autonomia política e territorial, livre circulação de fronteira, a exploração sexual, a violência contra as mulheres, o tráfico e o contrabando e saúde sexual e reprodutiva.

A problemática da mulher está enraizada em nossa sociedade e a conquista de direitos pelas mulheres tem se dado de forma lenta, mas com grandes avanços pela luta do movimento feminista que, em suas diversas ondas, pautou o direito político ao voto, ao acesso à educação, a inserção com maior igualdade no mercado de trabalho, o direito ao divórcio, a pressão por leis que protejam a mulher no mundo privado e a legalização do aborto.

Ainda assim, é possível perceber que temos muito que avançar para que as políticas públicas para mulheres ganhem mais espaço na cena institucional, havendo muitas lacunas, incoerências e contradições que permeiam a relação entre homens e mulheres, entre os diversos movimentos e no interior das instituições ${ }^{8}$.

\footnotetext{
${ }^{7}$ Projeto de extensão Universidade Popular dos Movimentos Sociais (UPMS): mulheres em diálogo de fronteira coordenado por uma das autoras, no ano de 2015, em articulação com a coordenadora do coletivo feminista Cotidiano Mujer, também autora deste artigo.

${ }^{8}$ Relatório Final da Universidade Popular dos Movimentos Sociais: mulheres em diálogo de fronteira. UFRGS (2015).
} 
De forma a enriquecer os debates e dar visibilidade ao maior número possível de mulheres, foram convidados movimentos, organizações e instituições da fronteira entre Brasil e Uruguai, não apenas de Santana do Livramento e Rivera, onde foi realizada a oficina.

Para que fosse possível a dinâmica e metodologia, a oficina foi dividida em três grupos de trabalho cujos temas nortearam os debates, trocas de experiências e construção de agendas:

\begin{tabular}{|c|l|l|}
\hline Grupo 1 & \multicolumn{1}{|c|}{ Grupo 2 } & \multicolumn{1}{|c|}{ Grupo 3 } \\
\hline Autonomia do Corpo & Autonomia Econômica & \multicolumn{1}{|c|}{ Putonomia Territorial e } \\
Política
\end{tabular}

Cada grupo realizou o debate durante um turno e apresentou as conclusões de seu grupo na Plenária final da oficina.

Algumas questões importantes foram debatidas no interior dos grupos. O grupo sobre autonomia do corpo foram discutidas questões como o abuso sexual na fronteira, a perda da laicidade das instituições públicas, a necessidade de formação de corpo docente em temas de vivências de gênero, a troca de experiências entre Uruguai e Brasil sobre parto humanizado e que a fronteira não seja usada como espaço de impunidade.

Em relação a autonomia econômica alguns pontos foram ressaltados como importantes para as mulheres da fronteira: a consciência sobre os direitos laborais; a existência de empregabilidade informal, baixa remuneração e subemprego; escassez de sustentabilidade de empreendimentos; discriminação (questões de gênero e afro), falta de possibilidade de regularização de trabalho informal e gerar políticas públicas específicas de fronteira. 
Por último em relação à autonomia política e territorial foram iluminados alguns temas: difusão de informação, documentação de fronteiras; representatividade/participação de mulheres árabes, idosas, trans, etc.; direito à cidadania: cidades seguras; mulheres e espaços públicos: assédio moral, falta de respeito e violação da individualidade.

Faz-se necessário ressaltar que no grande grupo foram discutidas a necessidade de formação de uma Rede Mulheres de Fronteira Brasil-Uruguai, a necessidade de continuar com a realização de atividades conjuntas de fronteira em níveis locais, incluir a cidades que não participaram, formação de espaços de encontro que deem relevância às mulheres afrodescendentes e as mulheres com deficiência.

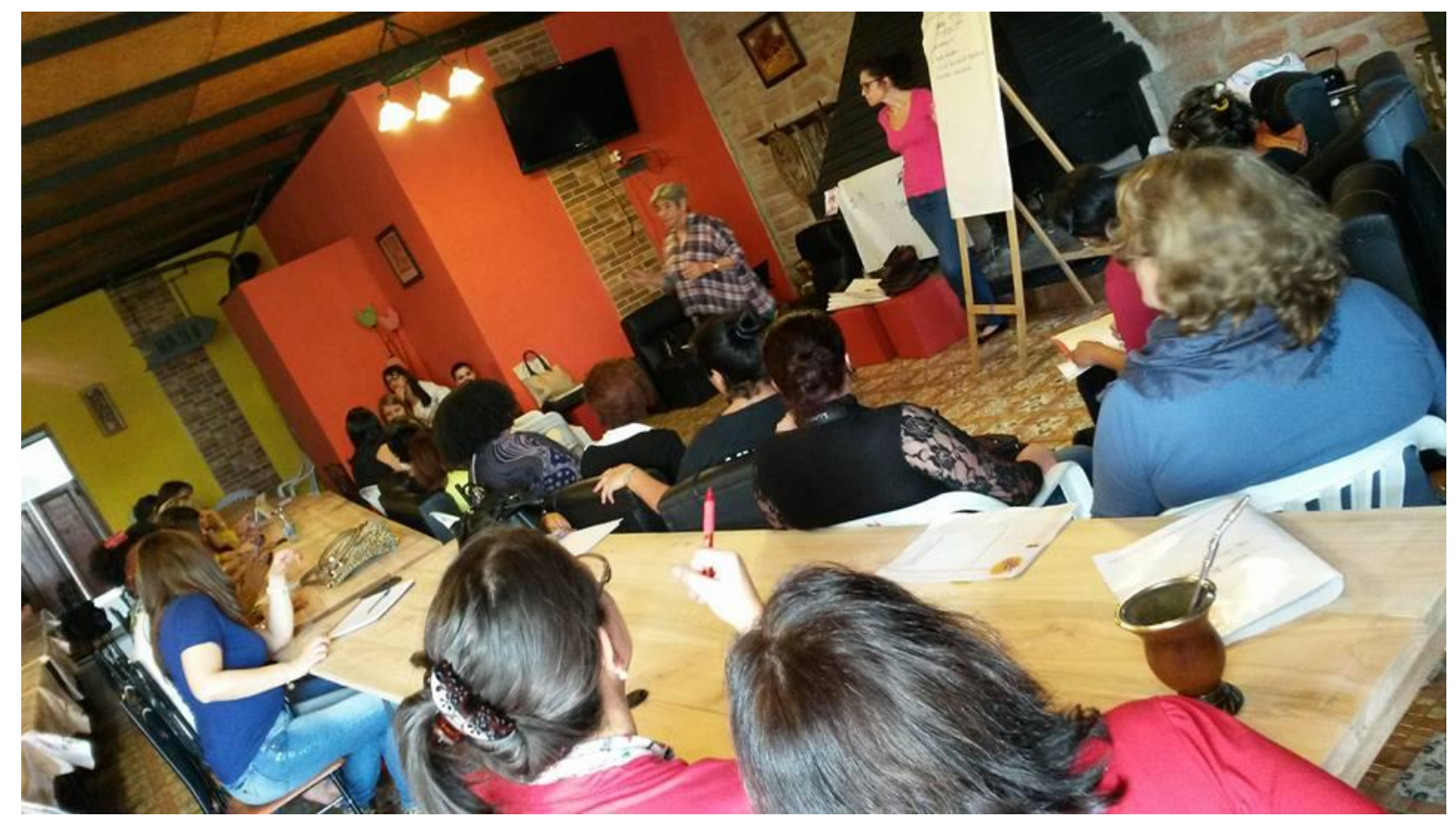

Foto 1: Plenária final da oficina UPMS: Mulheres em diálogo de fronteira. 


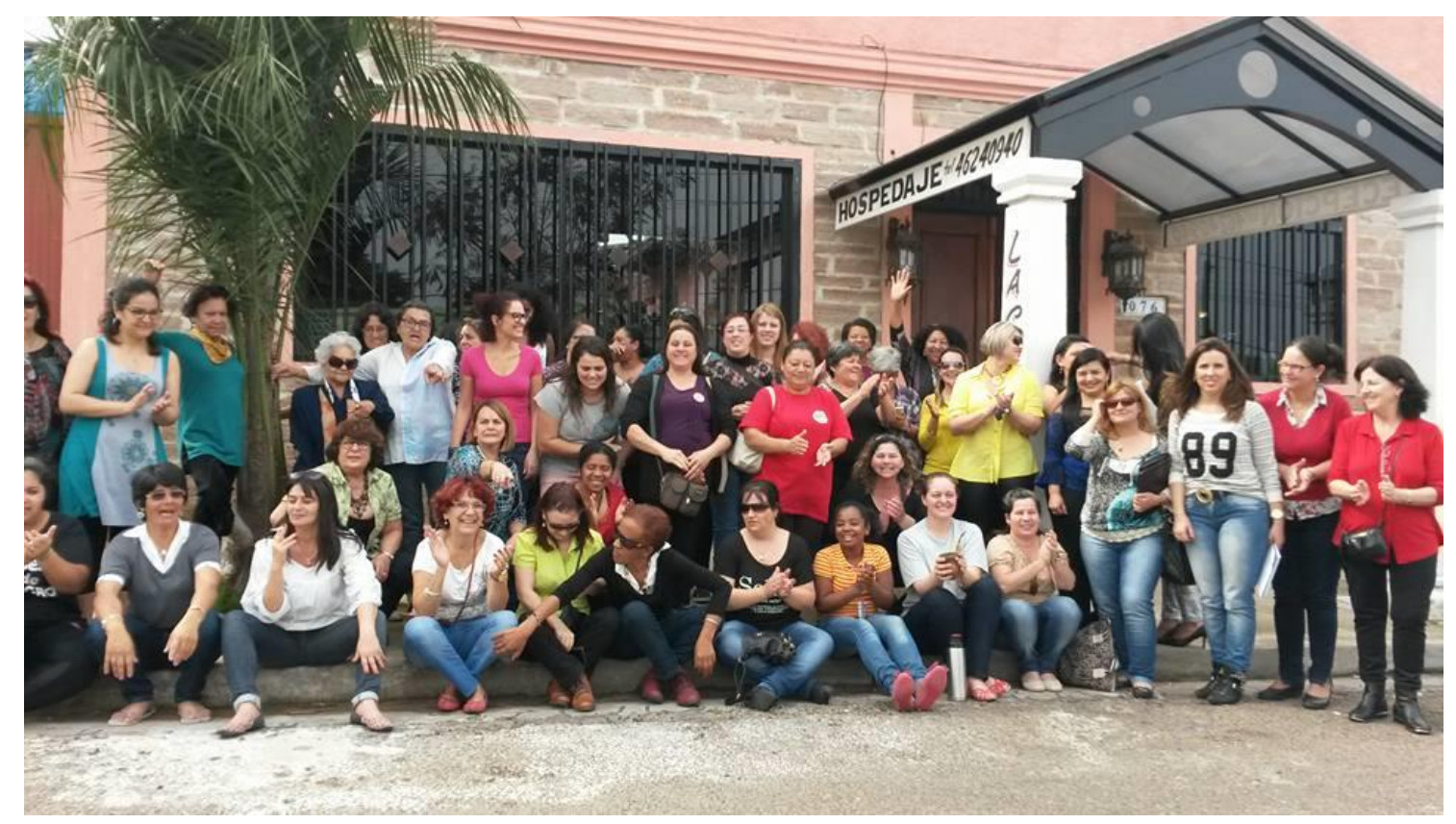

Foto 2: Equipe organizadora e participantes da oficina "Mulheres em Diálogo de Fronteira".

\section{Conclusões}

A partir do contexto adverso da globalização neoliberal com o surgimento do Fórum Social Mundial (FSM) houve uma internacionalização dos movimentos e de suas agendas. Esta mudança vem exigindo uma maior capacitação dos atores sociais e uma necessidade de articular-se entre si. Para o movimento feminista isto é ainda mais desafiante já que o pensamento patriarcal e subalternidade das mulheres está presente em todos os movimentos sociais.

O surgimento da Universidade Popular dos Movimentos Sociais (UPMS) no marco do Fórum Social Mundial (FSM), estimulou aos ativistas, militantes, acadêmicos e líderes dos movimentos e organizações sociais a organizar oficinas da UPMS para trocar suas experiências fundamentadas na ecologia dos saberes e na tradução cultural, criando novas pedagogias.

A proposta da UPMS busca romper não apenas com a visão tradicional e conservadora, mas também com aquelas concepções que não são capazes de reconhecer nos movimentos sociais sujeitos de construção de conhecimento. A relação baseada num diálogo intercultural, que reconheça os distintos saberes e não estabeleça uma hierarquia entre o saber formal do saber popular é fundamental neste processo. 
A oficina Mulheres em Diálogo de Fronteira colocou em evidência a necessidade de estabelecer esta troca a partir do Sul, desde perspectivas decoloniais com uma nova epistemologia do sul que desconstrua significados pautados pela colonialidade e pelo poder. O movimento feminista tem muito a contribuir neste sentido, pois ressignifica conceitos e categorias que incorporam a perspectiva de gênero, raça e natureza a partir das lutas e das histórias de vida dos sujeitos destes movimentos.

Fica evidente que a questão de gênero e raça não pode ser separada quando se fala de movimento de mulheres latino-americanas. A pluralidade no diálogo constitui-se como uma ferramenta política e emancipadora, onde a política feminista se constrói na diversidade e na diferença de olhares, mas que ao mesmo tempo converge em novas epistemologias, pedagogias e agendas.

\section{Referências}

AVILA, Maria Betânia; Notas sobre o trabalho doméstico. In: Transformando as Relaçoes Trabalho e Cidadania: produção, reprodução e sexualidade. Bahia: Núcleo de reflexão Feminista sobre trabalho produtivo e reprodutivo, 2007.

CARBY, Hazel.V, Mujeres blancas ¡escuchad! El feminismo negro y los límites de la hermandad femenina. En: Feminismos negros. Una antología. Traficantes de Sueños, Espanha, 2012.

CARNEIRO, Sueli. Ennegrecer al feminismo. Lola Press - Revista Feminista Internacional, Montevideo, Uruguay, v. 16, 2002.

CELIBERTI, Lilian. Imaginarios en disputa, In: Crisis y Movimientos sociales en nuestra América. DAZA, Mar, HOETMER, Raphael, VARGAS, Virginia. Peru: Editores. PDTG, 2012. ESCOBAR, Arturo. Mundos y conocimientos de otro modo. Tabula - rasa. Programa de investigación de modernidad/colonialidad latinoamericano. Departamento de Antropología, Universidad de Carolina del Norte (UNC). Chapel Hill. Instituto Colombiano de Antropología e Historia, Bogotá, 2003.

HARVEY, David. Espaços de Esperança. São Paulo: Loyola, 2006.

HABERMAS, Jürgen. Direito e Democracia: entre facticidade e validade.Rio de Janeiro: Tempo Brasileiro, 1997.

HELD, David. La democracia y el orden global. Del Estado moderno al gobierno cosmopolita.Barcelona: Paidós, 1997. 
MARX, Vanessa. A Universidade Popular dos Movimentos Sociais (UPMS): diálogo entre os movimentos sociais e universidade. In: XXX International Congress of the Latin America Studies Association (LASA). San Francisco, 2012.

MINGNOLO, Walter. Desobediencia epistémica. Retórica de la modernidad, lógica de la Colonialidad y gramática de la descolonialidad. Buenos Aires: Ediciones del Signo, 2011.

QUIJANO, Aníbal. “Colonialidade, poder, globalização e democracia”. Novos Rumos, v.17, n. 37, pp. 4-28, 2002.

. Colonialidad del poder, eurocentrismo y América Latina. En libro: La colonialidad del saber: eurocentrismo y ciencias sociales. Perspectivas Latinoamericanas. Edgardo Lander (comp.) CLACSO, Consejo Latinoamericano de Ciencias Sociales, Buenos Aires, Argentina. Julio de 2000. p. 246.

SOUSA SANTOS, Boaventura. A crítica da razao indolente. Contra o desperdício da experiencia. São Paulo: Editora Cortez, 2001.

Produzir para viver: os caminhos da produção não capitalista. Rio de Janeiro: Civilização Brasileira, 2002.

"A Universidade Popular dos Movimentos Sociais para formar ativistas e dirigentes dos movimentos sociais e ONGS e cientistas sociais intelectuais e artistas dedicados à transformação social. Uma proposta para discussão." Segunda versão. Coimbra: Universidade de Coimbra (CES), 2003.

. "Para além do pensamento abissal: das linhas globais a uma ecologia dessaberes". Novos Estudos n. 79 Novembro, 2007.

SOUSA SANTOS, Boaventura e AVRITZER, Leonardo "Para ampliar o cânone democrático" in SOUSA SANTOS, Boaventura de Sousa (Org.). Democratizar a democracia. Rio de Janeiro: Ed. Civilização Brasileira, 2009.

UNIVERSIDADE POPULAR DOS MOVIMENTOS SOCIAIS: http://www.universidadepopular.org/site/pages/pt/oficinas/oficina-de-porto-alegre---2010.php Acessado em 28/05/2016.

WALSH, Catherine. Pensamiento crítico y matriz (de) colonial. Reflexiones Latinoamericanas”. Equador: Abya Yala/UPS Publicaciones. Universidad Andina Simón Bolivar, 2005.

Recebido em: 31/01/2017. Aprovado em: 21/03/2017. 